\title{
Influence of Anionic Surfactants on Fundamental Properties of Polymer/Reduced Graphene Oxide Nanocomposite Films
}

Vipul Agarwal, ${ }^{1 *}$ Yasemin Fadil, ${ }^{1}$ Alice Wan, ${ }^{1}$ Namrata Maslekar, ${ }^{1}$ Bich Ngoc Tran, ${ }^{1}$ Rabiatul A. Mat Noor, ${ }^{1}$ Saroj Bhattacharyya, ${ }^{2}$ Joanna Biazik, ${ }^{2}$ Sean Lim, ${ }^{2}$ Per B. Zetterlund ${ }^{1 *}$

${ }^{1}$ Cluster for Advanced Macromolecular Design (CAMD), School of Chemical Engineering, University of New South Wales, Sydney, NSW 2052, Australia

${ }^{2}$ Mark Wainwright Analytical Centre, University of New South Wales, Sydney, NSW, 2052, Australia

*Corresponding authors: agarwalvipul84@gmail.com, p.zetterlund@unsw.edu.au

\section{Supporting Information}

Table S1: Droplet and particle size (DLS) data of St/nBA/GO (5 wt $\%)$ polymer latexes at different concentrations of SDS.

\begin{tabular}{|c|c|c|c|c|c|}
\hline \multirow[t]{2}{*}{ SDS (\%) } & \multicolumn{2}{|c|}{$\begin{array}{c}\text { Droplet Intensity Average } \\
\text { Diameter (nm) }\end{array}$} & \multirow[t]{2}{*}{$\begin{array}{c}\text { Conversion } \\
(\%)\end{array}$} & \multicolumn{2}{|c|}{$\begin{array}{c}\text { Particle Intensity Average } \\
\text { Diameter (nm) }\end{array}$} \\
\hline & Size (nm) & PDI & & Size (nm) & PDI \\
\hline 1 & - & 0.4 & 92 & 45 & 0.9 \\
\hline 2 & 442 & 0.5 & 92 & 15 & 0.8 \\
\hline 3 & 236 & 0.4 & 93 & 63 & 0.3 \\
\hline 4 & 328 & 0.5 & 94 & 68 & 0.2 \\
\hline 5 & 482 & 0.5 & 94 & 64 & 0.2 \\
\hline 7 & 378 & 0.5 & 90 & 133 & 0.3 \\
\hline
\end{tabular}

Table S2: Droplet and particle size (DLS) data of $\mathrm{St} / n \mathrm{BA} / \mathrm{GO}(5 \mathrm{wt} \%)$ polymer latexes at different concentrations of SDBS.

\begin{tabular}{|c|c|c|c|c|c|}
\hline \multirow[t]{2}{*}{ SBDS (\%) } & \multicolumn{2}{|c|}{$\begin{array}{c}\text { Droplet Intensity Average } \\
\text { Diameter (nm) }\end{array}$} & \multirow[t]{2}{*}{$\begin{array}{c}\text { Conversion } \\
(\%)\end{array}$} & \multicolumn{2}{|c|}{$\begin{array}{c}\text { Particle Intensity Average } \\
\text { Diameter (nm) }\end{array}$} \\
\hline & Size (nm) & PDI & & Size $(\mathrm{nm})$ & PDI \\
\hline 1 & 292 & 0.4 & 93 & 84 & 1.9 \\
\hline 4 & 219 & 0.4 & 100 & 105 & 0.2 \\
\hline 7 & 525 & 0.6 & 94 & 65 & 0.2 \\
\hline
\end{tabular}

Table S3: Number-average $\left(M_{\mathrm{n}}\right)$ and weight-average $\left(M_{\mathrm{w}}\right)$ molecular weights and dispersity $(\bigoplus)$ for $\mathrm{St} / n \mathrm{BA} / \mathrm{GO}(5 \mathrm{wt} \%)$ polymers at different concentrations of SDS.

\begin{tabular}{|c|c|c|c|}
\hline SDS (\%) & $\left.\boldsymbol{M}_{\mathbf{n}}(\mathbf{x ~ 1 0}) \mathbf{~} \mathbf{( g} / \mathbf{m o l}\right)$ & $\left.\boldsymbol{M}_{\mathbf{w}}(\mathbf{x ~ 1 0}) \mathbf{( g} / \mathbf{m o l}\right)$ & $\boldsymbol{D}$ \\
\hline 1 & 17.7 & 44.7 & 2.5 \\
\hline 2 & 16.0 & 45.9 & 2.9 \\
\hline 3 & 24.4 & 61.8 & 2.5 \\
\hline 4 & 24.7 & 58.3 & 2.4 \\
\hline 5 & 28.6 & 67.0 & 2.3 \\
\hline
\end{tabular}


Table S4: Number-average $\left(M_{\mathrm{n}}\right)$ and weight-average $\left(M_{\mathrm{w}}\right)$ molecular weights and dispersity $(\bigoplus)$ for $\mathrm{St} / n \mathrm{BA} / \mathrm{GO}(5 \mathrm{wt} \%)$ polymers at different concentrations of SDBS.

\begin{tabular}{|c|c|c|c|}
\hline SDBS (\%) & $\left.\left.\boldsymbol{M}_{\mathbf{n}} \mathbf{( x ~ 1 0} \mathbf{4}\right) \mathbf{( g / m o l}\right)$ & $\left.\left.\boldsymbol{M}_{\mathbf{w}} \mathbf{( x ~ 1 0} \mathbf{~}\right) \mathbf{( g / m o l}\right)$ & $\boldsymbol{D}$ \\
\hline 1 & 18.6 & 44.3 & 2.4 \\
\hline 4 & 19.7 & 64.3 & 3.3 \\
\hline 7 & 22.4 & 69.1 & 3.1 \\
\hline
\end{tabular}

Table S5: Raman data showing the $\mathrm{D}$ and $\mathrm{G}$ peaks positions and the $\mathrm{I}_{\mathrm{D}} / \mathrm{I}_{\mathrm{G}}$ ratios calculated from Lorentzian fitting of the deconvoluted $\mathrm{D}$ and $\mathrm{G}$ peaks obtained for films fabricated using SDS shown in Figure S2a.

\begin{tabular}{|c|c|c|c|}
\hline SDS (\%) & D Peak $\left.\mathbf{( c m}^{-1}\right)$ & G Peak $\left.\mathbf{( c m}^{-1}\right)$ & $\mathbf{I}_{\mathbf{D}} / \mathbf{I}_{\mathbf{G}}$ \\
\hline 1 & 1351.80 & 1587.05 & 0.73 \\
\hline 2 & 1352.22 & 1586.88 & 0.76 \\
\hline 3 & 1351.57 & 1586.30 & 0.74 \\
\hline 4 & 1351.67 & 1586.45 & 0.74 \\
\hline 5 & 1350.81 & 1586.00 & 0.73 \\
\hline 7 & 1352.08 & 1585.87 & 0.72 \\
\hline
\end{tabular}

Table S6: Raman data showing the $\mathrm{D}$ and $\mathrm{G}$ peaks positions and the $\mathrm{I}_{\mathrm{D}} / \mathrm{I}_{\mathrm{G}}$ ratios calculated from Lorentzian fitting of the deconvoluted $\mathrm{D}$ and $\mathrm{G}$ peaks obtained for films fabricated using SDBS shown in Figure S2b.

\begin{tabular}{|c|c|c|c|}
\hline SDBS (\%) & D Peak $\mathbf{( c m}^{-\mathbf{1}} \mathbf{)}$ & $\mathbf{G}$ Peak $\left.\mathbf{( c m}^{-\mathbf{1}}\right)$ & $\mathbf{I}_{\mathbf{D}} / \mathbf{I}_{\mathbf{G}}$ \\
\hline 1 & 1352.29 & 1587.50 & 0.72 \\
\hline 4 & 1353.77 & 1586.88 & 0.67 \\
\hline 7 & 1353.13 & 1586.67 & 0.73 \\
\hline
\end{tabular}

Table S7: Electrical conductivity of thermally reduced nanocomposite films containing different concentrations of SDS. Data is representative of 2 individual films and 3 measurements per film and presented as average \pm standard deviation (SD).

\begin{tabular}{|c|c|}
\hline SDS (\%) & Electrical conductivity (S/m) \\
\hline 1 & $1.07 \pm 0.03$ \\
\hline 2 & $1.38 \pm 0.15$ \\
\hline 3 & $2.46 \pm 0.32$ \\
\hline 4 & $2.98 \pm 0.01$ \\
\hline 5 & $2.83 \pm 0.65$ \\
\hline 7 & $4.38 \pm 0.09$ \\
\hline
\end{tabular}

Table S8: Electrical conductivity of thermally reduced nanocomposite films containing different concentrations of SDBS. Data is representative of 2 individual films and 3 measurements per film and presented as average \pm standard deviation (SD). 


\begin{tabular}{|c|c|}
\hline SDBS (\%) & Electrical conductivity (S/m) \\
\hline 1 & $0.21 \pm 0.01$ \\
\hline 4 & $0.22 \pm 0.01$ \\
\hline 7 & $0.38 \pm 0.02$ \\
\hline
\end{tabular}

Table S9: Mechanical properties of nanocomposite films containing different concentrations of SDS. Data are presented as an average \pm standard deviation of three independent films.

\begin{tabular}{|c|c|c|}
\hline SDS (\%) & Tensile strength (MPa) & Young's modulus (MPa) \\
\hline 1 & $3.91 \pm 1.04$ & $53.91 \pm 9.69$ \\
\hline 2 & $3.35 \pm 0.45$ & $55.16 \pm 21.52$ \\
\hline 3 & $3.58 \pm 0.52$ & $60.47 \pm 29.65$ \\
\hline 4 & $3.93 \pm 0.58$ & $60.44 \pm 31.17$ \\
\hline 5 & $4.13 \pm 0.44$ & $51.9 \pm 14.08$ \\
\hline 7 & $3.9 \pm 0.19$ & $81.98 \pm 11.36$ \\
\hline
\end{tabular}

Table S10: Mechanical properties of the nanocomposite films containing different concentrations of SDBS. Data are presented as an average \pm standard deviation of three independent films.

\begin{tabular}{|c|c|c|}
\hline SDBS (\%) & Tensile strength (MPa) & Young's modulus (MPa) \\
\hline 1 & $3.69 \pm 0.13$ & $63.37 \pm 4.16$ \\
\hline 4 & $1.69 \pm 0.09$ & $14.20 \pm 1.73$ \\
\hline 7 & $2.55 \pm 0.15$ & $29.05 \pm 2.50$ \\
\hline
\end{tabular}


Supporting Information

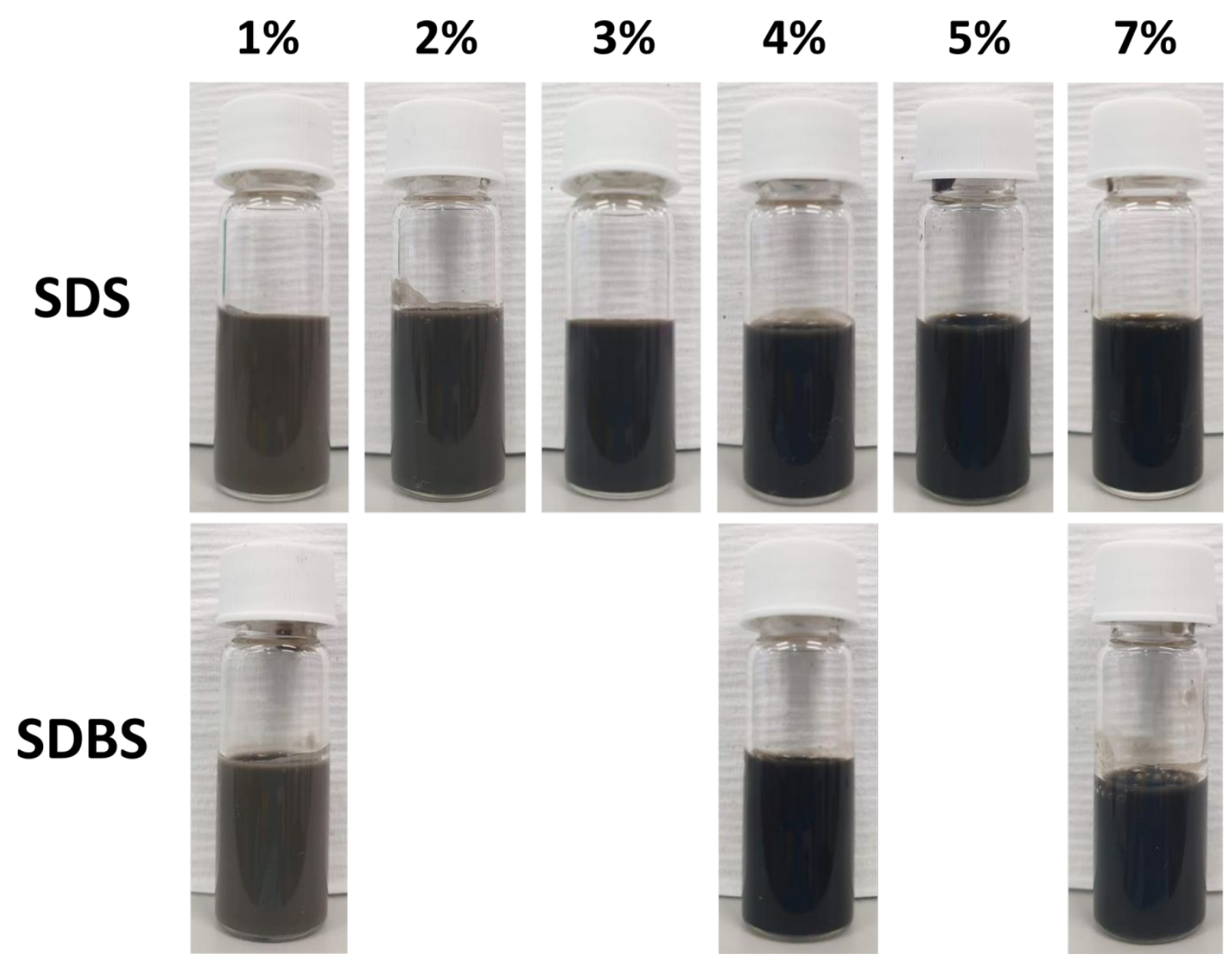

Figure S1. Images of the nanocomposite latexes synthesised using different concentrations of surfactants (SDS and SDBS). 

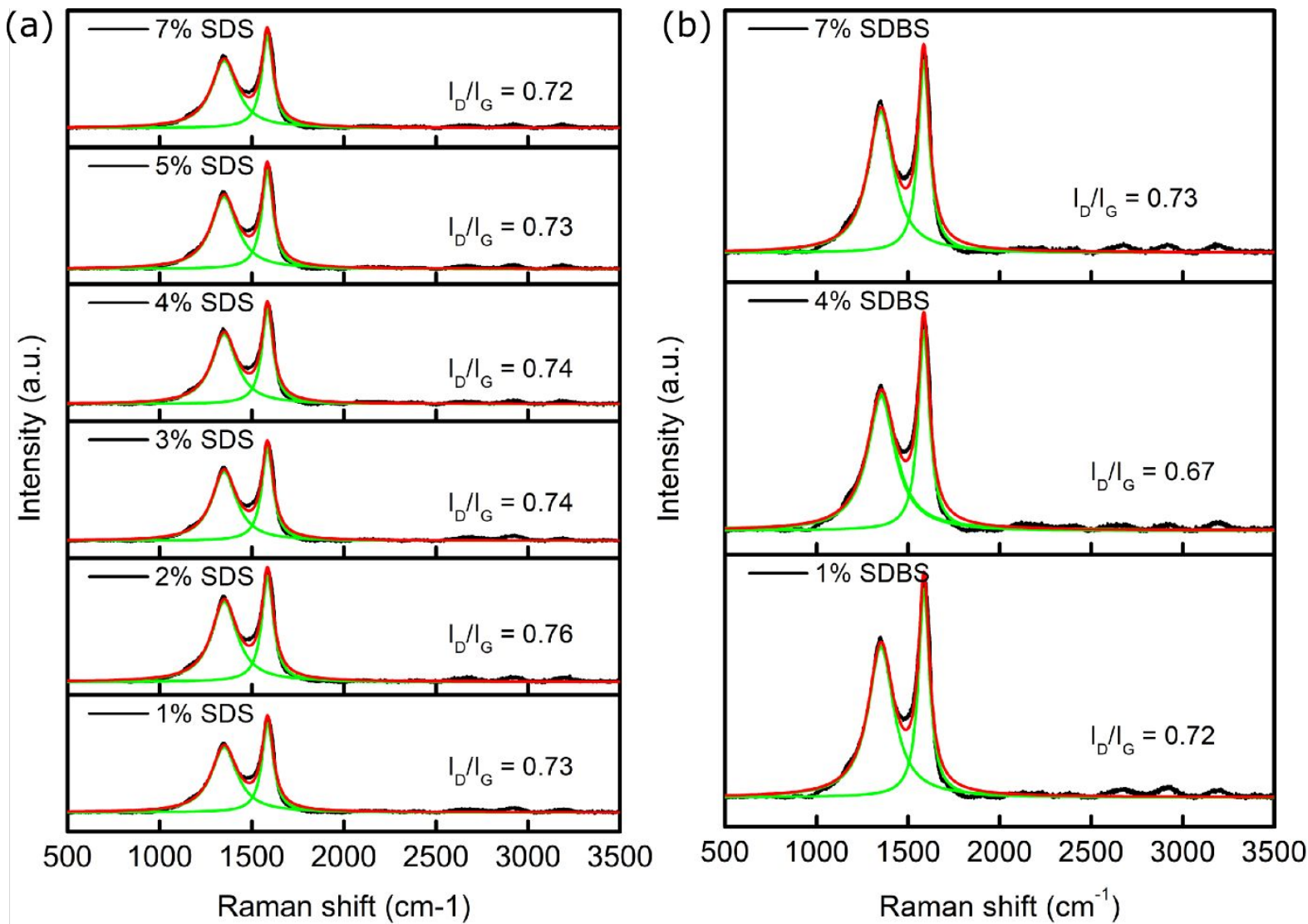

Figure S2. Raman analysis of $\mathrm{p}(\mathrm{St}-$ stat $-n \mathrm{BA}) / \mathrm{rGO}$ nanocomposite films containing different concentrations of (a) SDS, (b) SDBS. 


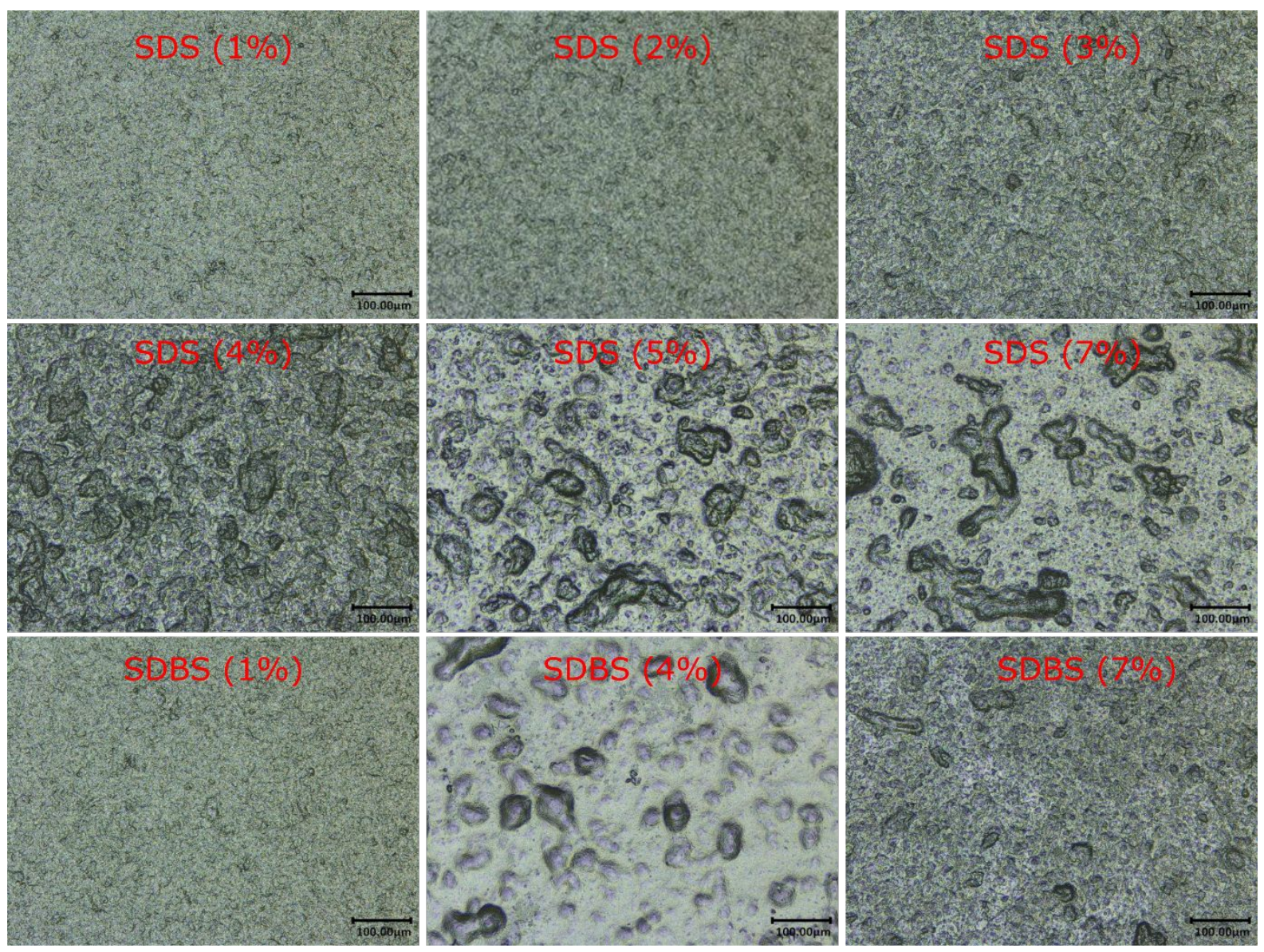

Figure S3. Additional confocal laser scanning microscopy images showing surface morphology of the $\mathrm{p}(\mathrm{St}-\mathrm{stat}-\mathrm{nBA}) / \mathrm{GO}$ nanocomposite films fabricated using different concentrations of SDS and SDBS. Scale bar: $100 \mu \mathrm{m}$. 

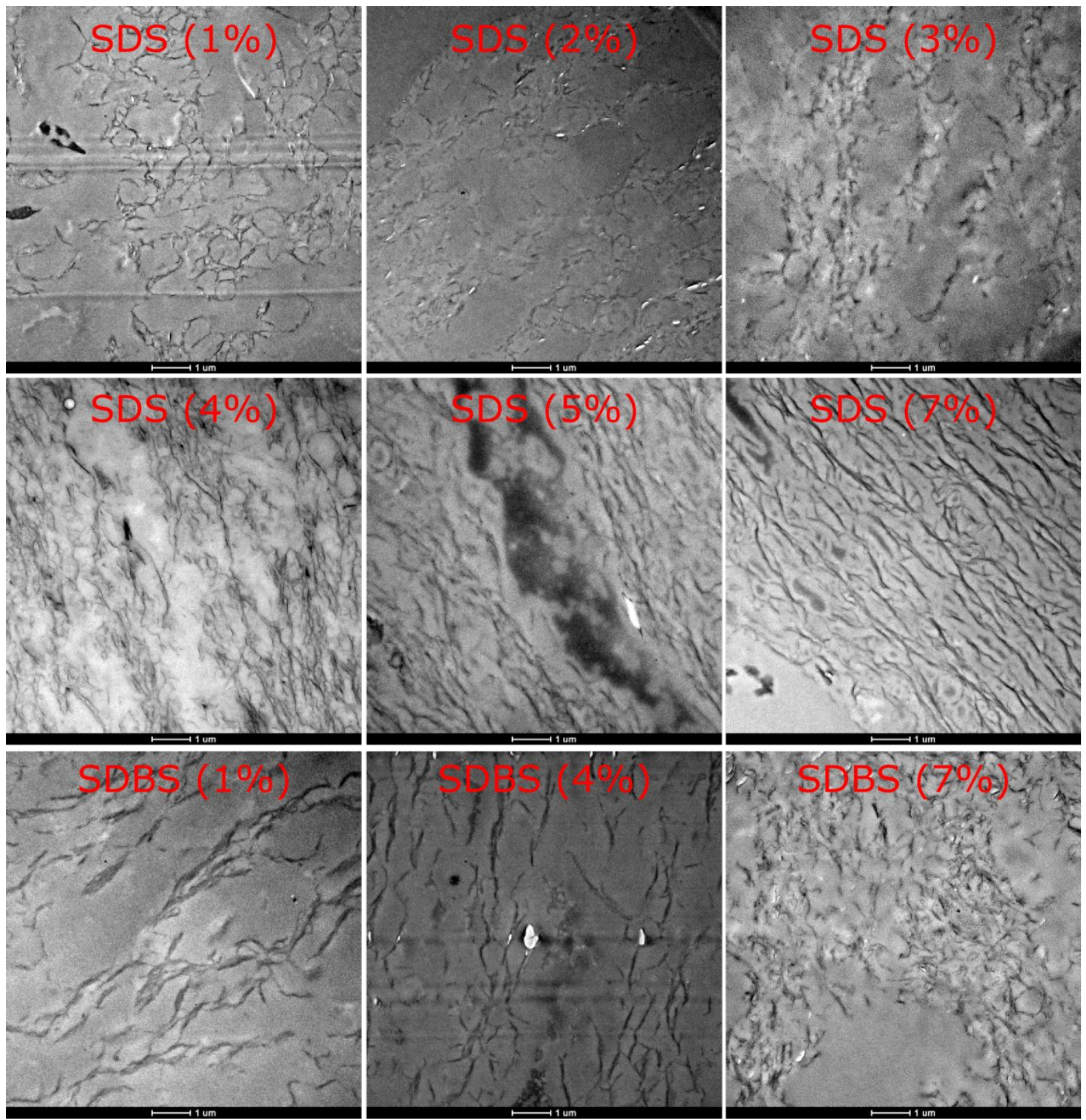

Figure S4. Additional cross-sectional TEM images of the $\mathrm{p}(\mathrm{St}-\mathrm{stat}-n \mathrm{BA}) / \mathrm{GO}$ nanocomposite films showing the distribution of GO sheets within the polymer matrix (dark features represent GO sheets and grey background corresponds to coalesced polymer particle film). Scale bar: $1 \mu \mathrm{m}$. 

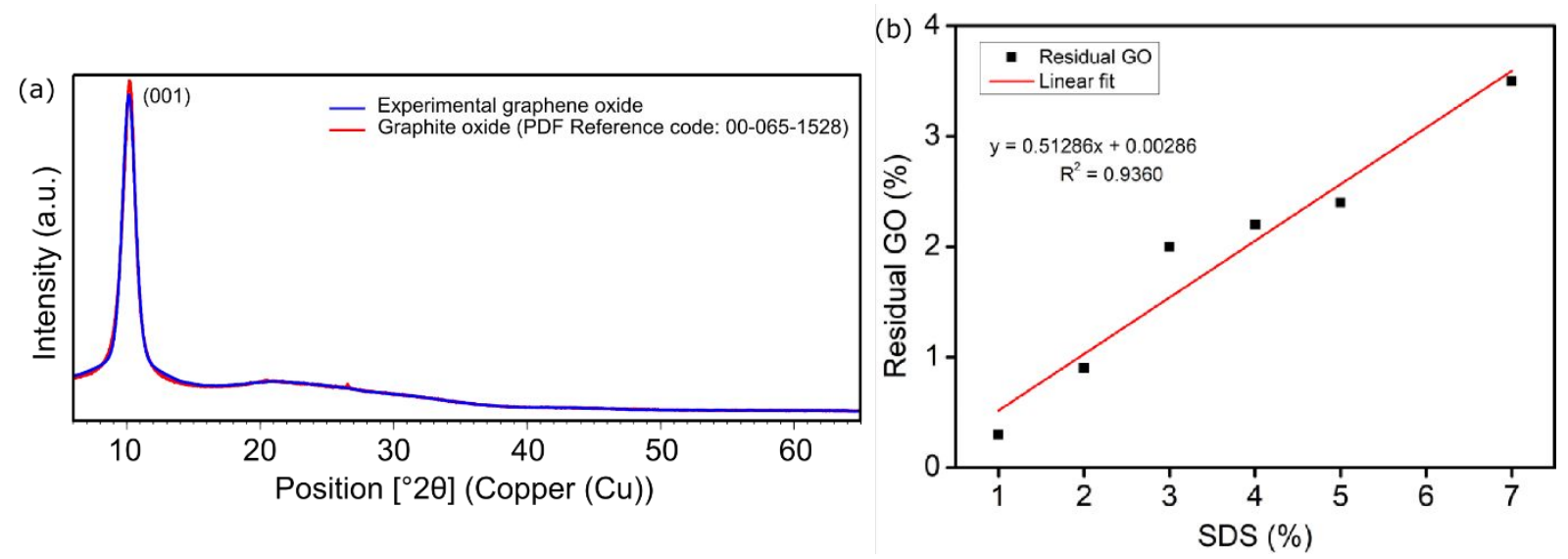

Figure S5. (a) XRD comparison of GO pattern with graphite oxide in the ICDD database showing the overlapping pattern confirming the 001 peak in GO. (b) correlation between residual GO in the films and SDS concentration.

\section{XRD data analysis}

The Full Pattern Autoscale analysis was conducted to obtain the extent of residual GO in films containing different concentrations of SDS. The method works on the principle that powder XRD patterns of each individual component in a mixture can reproduce the obtained experimental pattern, when added in proper proportions after corrected for absorption and matrix effects. ${ }^{1}$ We conducted Full Pattern Autoscale analysis by first acquiring the XRD pattern of individual component of the nanocomposite i.e. (p(St-stat-nBA)) containing SDS (7 $\mathrm{wt} \%$ ), pure SDS and pure GO under same data collection parameters. The obtained spectra were analysed using HighScore Plus instrument software, which matched them to develop a 'theoretical' XRD pattern based on a specific theoretical model (software develops after combining and matching entire XRD patterns instead of individual peaks in the XRD patterns of individual components). The software then applies the specific theoretical model to the experimentally obtained XRD patterns of the films and determine the contribution of individual peaks. In this case, we first validated the characteristic $001 \mathrm{GO}$ peak at $2 \theta=\sim 10.5^{\circ}$ in our pure GO sample against the XRD pattern of GO from the ICDD database. Following which, XRD patterns of films fabricated using different concentrations of SDS were subjected to Full Pattern Autoscale analysis to obtain the contribution of residual GO (001) peak, which is presented in Figure S5b. 'Residual GO' is defined as amount of GO (non-reduced GO) present in the films after thermal annealing. For example, 3.5\% residual GO meant that $96.5 \%$ of GO in the film got reduced during the thermal annealing.

\section{References}

(1) Smith, D. K.; Johnson, G. G.; Scheible, A.; Wims, A. M.; Johnson, J. L.; Ullmann, G. Quantitative X-ray powder diffraction method using the full diffraction pattern. Powder Diffraction 1987, 2 (2), 73-77. 